\title{
Immune Activation in HIV-Infected Patients Treated with Different ARV Regimens
}

\author{
Alessia Uglietti ${ }^{1}$, Sergio Lo Caputo ${ }^{2}$, Marinella Lauriola ${ }^{1}$, Michele De Gennaro ${ }^{3}$, \\ Elisabetta Chiesa ${ }^{4}$, Massimo Coen ${ }^{4}$, Roberta Terzi ${ }^{4}$, Dorothy H. Bray ${ }^{5}$, Renato Maserati ${ }^{1}$, \\ Daria Trabattoni ${ }^{6 *}$, Mario Clerici ${ }^{6,7}$
}

\begin{abstract}
${ }^{1}$ Departments of Infectious Diseases of the Foundation IRCCS Policlinico San Matteo Hospital, Pavia, Italy; ${ }^{2}$ Departments of Infectious Diseases of the Santa Maria Annunziata Hospital, Firenze, Italy; ${ }^{3}$ Departments of Infectious Diseases of the Campo di Marte Hospital, Milano, Italy; ${ }^{4}$ Departments of Infectious Diseases of the Luigi Sacco Hospital, Milano, Italy; ${ }^{5}$ Departments of Infectious Diseases of the Immunoclin Ltd., Paris, France; ${ }^{6}$ Departments of Infectious Diseases of the Chair of Immunology, University of Milano, Milano, Italy; ${ }^{7}$ Departments of Infectious Diseases of the Fondazione Don C. Gnocchi, Scientific Institute for Patient Care and Research, Milano, Italy.

Email: *daria.trabattoni@unimi.it
\end{abstract}

Received February $1^{\text {st }}, 2012$; revised March $28^{\text {th }}, 2012$; accepted April $26^{\text {th }}, 2012$

\begin{abstract}
Objectives: To evaluate the effects of starting therapy with either Truvada (TVD) or Combivir (CBV) in combination with Efavirenz (EFV) or a boosted Protease Inhibitor (LPV/r, ATV/r, fAPV/r and SQV/r) on clinical, immunological, and virological parameters in HIV-infected antiretroviral (ARV) naive patients. Methods: Twenty-seven patients were prospectively enrolled and received TVD-EFV, 32 TVD-PI/r, 24 CBV-EFV, and 23 CBV-PI/r. Immunovirological analyses were performed at baseline and after 3,6,9 and 12 months after initiation of therapy; a full set of data is available for 51 patients. Results: Median CD4+ cell counts and HIV-RNA plasma viremia were comparable in the four groups of patients (TVD-EFV, TVD-PI/r, CBV-EFV, CBV-PI/r) at baseline. At month 12 HIV RNA plasma viremia was $<50 \mathrm{cps} / \mathrm{ml}$ in all patients. Median CD4 cell counts increases were higher, although not significantly, in CBV-EFV and TVD-EFV patients. Finally, CD8+/CD38+/CDRO+ T lymphocytes were significantly decreased after 12 months of therapy in all patients with, possibly, a faster effect seen in the EFV groups. Conclusions: Immunologic parameters are similarly affected by different ARV combinations, even if EFV-associated immunomodulation might be marginally better.
\end{abstract}

Keywords: HIV; Immune Activation; Antiretroviral Therapy

\section{Introduction}

$\mathrm{T}$ cell activation is an important parameter for predicting disease progression in HIV-positive, untreated patients independently of HIV viral load and CD4+ T cell counts $[1,2]$. Antiretroviral therapy (ARV) reduces $\mathrm{T}$ cell activation, but this parameter may remain abnormally elevated even after years of HIV-RNA undetectability $[3,4]$. Persistent immune activation is associated with a blunted recovery of CD4+ T cells and augmented susceptibility to the development of HIV infection-associated comorbidities [5].

The impairment of a number of immune parameters, involving multiple cell types, characterizes immune activation in HIV patients. Thus, cells expressing HLA-DR, CD25, CD69, and CD70, as well as serum levels of neopterin, tumor necrosis factor receptor type II, and

${ }^{*}$ Corresponding author. beta2-microglobulin are known to concur to this phenomenon [6,7]. The most important, and the best characterized index of immune activation seen in HIV infection is nevertheless the increase of $\mathrm{CD} 8+/ \mathrm{CD} 38+/ \mathrm{CD} 45 \mathrm{RO}+$ $\mathrm{T}$ lymphocytes. Increases in these cells are known to be a strong predictor of progression to AIDS independently of CD4 counts $[1,8,9]$ and to predict the likelihood to achieve an optimal suppression of viremia in naïve patients starting therapy [10]. CD38 is a multifunctional transmembrane glycoprotein that is up-regulated during the earliest stages of T cell activation [11,12]. Deeks and co-workers found that the initiation of antiretroviral therapy during early HIV infection reduces the level of $\mathrm{CD} 8+\mathrm{T}$ cell activation and, to a lesser degree, also that of CD4+ T cell activation [13]. Different HAART combinations may have a different effect on $\mathrm{T}$ cell activation markers. We investigated the expression of activation markers in a group of naïve HIV-positive patients start- 
ing different ARV combinations containing either emtricitabine plus tenofovir fixed-dose combination (Tru$\operatorname{vada}^{\circledR}$, TVD) vs. lamivudine plus zidovudine FDC (Combivir $\left.^{\circledR}, \mathrm{CBV}\right)$, given with efavirenz (EFV) or a ritonavirboosted protease inhibitor $(\mathrm{PI} / \mathrm{r})$.

\section{Methods}

\subsection{Study Population}

Naïve patients eligible for treatment in 5 partecipating Clinical Centres were selected for this study if treated with one of these four HAART combinations: 1) TVD plus EFV); 2) CBV plus EFV; 3) TVD plus PI/r; 4) CBV plus $\mathrm{PI} / \mathrm{r}$. Patients were followed every 3 months after having started the ARV treatment, and were assessed locally for clinical and laboratory parameters. They were also sampled at baseline (pre-treatment) and 3, 6 and 12 months after treatment start for a series of immunological determinations performed centrally at the Immunology Laboratory of the Milano University. The study protocol was approved by local Ethical Committees of participating Clinical Centres and all the patients signed an informed consent before enrolment.

\subsection{Blood Sample Collection and CD4 T Cell Count}

Whole blood was collected by venipuncture in Vacutainer tubes containing EDTA (ethylenediaminetetraacetic acid) (Becton Dickinson, Rutherford, NJ).

The absolute numbers of CD4 $\mathrm{T}$ cells were determined in fresh blood with an Epics XL-MCL flow cytometer (Beckman Coulter).

\subsection{Immunophenotipic Analysis}

Surface proteins were evaluated using $50 \mu \mathrm{l}$ of EDTA peripheral blood. Cells were incubated for $30 \mathrm{~min}$ at $4{ }^{\circ} \mathrm{C}$ with the following flourochrome labeled mAbs: CD4R-Phycoerythrin-Cyanine 5 Tandem-PE-Cy5 (mouse IgG1 isotype, Beckman Coulter, Fullerton CA), CD8-R-Phycoerythrin-Cyanine 5 Tandem-PE-Cy5 (mouse IgG1 isotype, Beckman Coulter, Fullerton CA), HLA-DR-Phycoerythrin (mouse IgG1 isotype, Beckman Coulter, Fullerton CA), CD38-Phycoerythrin (mouse IgG1 isotype, Beckman Coulter, Fullerton CA), CD25-Phycoerythrin (mouse IgG1 isotype, eBioscience, San Diego, CA), CD8-Fluorescein-isothiocyanate (mouse IgG1 isotype, Beckman Coulter, Fullerton CA), CD45RO-Fluoresceinisothiocyanate (mouse IgG1 isotype, Beckman Coulter, Fullerton CA). After incubation, erythrocyte lysis and fixation of marked cells was performed using ImmunoPrep EPICS Kit (Coulter Electronics, miami Lakes, FL) and Q-prep Work Station (Coulter Electronics, miami Lakes, FL). Cytometric analysis were performed using an
EPICS XL flow cytometer (Beckman Coulter Inc., Miami, FL) equipped with a single $15 \mathrm{~mW}$ argon ion laser operating at $488 \mathrm{~nm}$ interfaced with 486 DX2 IBM computer. Data were collected using linear amplifiers for forward and side scatters and logarithmic amplifiers for FL1, FL2 and FL4. Samples were first run using isotype control or single fluorochrome-stained preparations for color compensation. For each sample, multiparametric data were acquired for 200,000 events.

\subsection{Statistical Analysis}

Comparisons between the different groups were carried out with two-sided Fisher's exact test. Quantitative continuous variables were normally distributed and comparisons were performed using paired samples T-test. Statistically significant differences were considered those with a $\mathrm{p}$ value $<0.05$.

\section{Results}

\subsection{Study Population and Clinical Efficacy}

One hundred and six HIV-infected, ARV-naïve patients were prospectively enrolled and treated with TVD or $\mathrm{CBV}$ in combination with $\mathrm{EFV}$ or a $\mathrm{PI} / \mathrm{r}(\mathrm{LPV} / \mathrm{r}, \mathrm{ATV} / \mathrm{r}$, fAPVr and SQV/r). The baseline characteristics of the 4 groups of patients are shown in Table 1(a).

Fifty-one individuals have reached 12 months of therapy. EFV-associated skin rash was observed in three of the TVD- and in one of the CBV-treated patients after a few days of starting therapy. Eight patients in the TVD groups (3 TVD-EFV and $5 \mathrm{TVD}-\mathrm{PI} / \mathrm{r}$ ) and 9 patients in the $\mathrm{CBV}$ groups (6 CBV-EFV and $3 \mathrm{CBV}-\mathrm{PI} / \mathrm{r}$ ) dropped out of the study; in only two cases (1 TVD: acute pancreatitis; $1 \mathrm{CBV}$ : leucopenia) the drop-out was due to serious adverse events (SAE), as shown in Table 1(b).

Clinical, immunological and virologic parameters at baseline and after 12 months of therapy are presented here in the individuals who reached 12 months of therapy. Median CD4+ cell counts and percentages as well as HIV-RNA plasma viremia were comparable in the four groups at baseline.

The virological effect of all therapies was comparable as at month 12 HIV-RNA plasma viremia was $<50 \mathrm{cps} /$ $\mathrm{ml}$ in all patients. CD4+ $\mathrm{T}$ cell counts increased significantly compared to baseline in all groups of patients; the increase was more notable in both groups of EFV-treated patients (TDV-EFV $=462 / \mathrm{mcl}(\mathrm{IQR}: 323$ - 6635), CBV$\mathrm{EFV}=450 / \mathrm{mcl}(\mathrm{IQR}: 388,75-525,75)$ compared to those individuals receiving $\mathrm{PI} / \mathrm{r}(\mathrm{TDV}-\mathrm{PI} / \mathrm{r}=339 / \mathrm{mcl}$ (IQR: 298 - 365), CBV-PI/r = 390/mcl (IQR: 308 - 523). (Figure 1, Panel (a)).

CD4+ T cell percentages were significantly increased at month 12 in TVD-EFV $(\mathrm{p}<0.001)$, TVD-PI/r $(\mathrm{p}=$ 
Table 1. (a) Demographic and clinical characteristics of patients enrolled in the study at baseline; (b) Drop-outs for adverse events and toxicity.

(a)

\begin{tabular}{ccccc}
\hline & TVD-EFV & TVD-PI & CBV-EFV & CBV-PI \\
\hline Mean age, yrs (range) & $44(33-70)$ & $47(33-66)$ & $48(32-73)$ & $43(32-76)$ \\
Sex (M/F) & $26 / 1$ & $24 / 8$ & $22 / 2$ & $20 / 3$ \\
CDC'93: C3 & 6 & 19 & 7 & 7 \\
Median CD4+ cell/ $\mu$ L (IQR) & $242(94-312)$ & $115(44-174)$ & $206(71-289)$ & $184(95-270)$ \\
Median HIV-RNA cps/mL (IQR) & $147,070(26,065-194,000)$ & $118,306(97,593-377,550)$ & $107,300(23,984-268,424)$ & $78,630(44,757-177,325)$ \\
\hline
\end{tabular}

(b)

\begin{tabular}{|c|c|c|c|c|}
\hline \multirow{2}{*}{ Treatment group } & \multirow{2}{*}{ Lost to follow-up* } & \multicolumn{3}{|c|}{ Drop-out for adverse events, toxicities } \\
\hline & & At month 3 & At month 6 & At month 12 \\
\hline TVD-EFV & 10 & & Acute pancreatitis (1) & $\begin{array}{l}\text { Creatinine increase (1) } \\
\text { Triglyceride increase (1) }\end{array}$ \\
\hline TVD-PI/r & 9 & $\begin{array}{l}\text { Creatinine increase (1) } \\
\text { Nausea and vomiting (1) }\end{array}$ & & $\begin{array}{l}\text { Creatinine increase (1) } \\
\text { Triglyceride increase (1) } \\
\text { Immunological failure (1) }\end{array}$ \\
\hline CBV-EFV & 10 & $\begin{array}{l}\text { CNS symptoms (1) } \\
\text { Virological failure (1) }\end{array}$ & $\begin{array}{c}\text { CNS symptoms (1) } \\
\text { Nausea and vomiting (1) }\end{array}$ & $\begin{array}{c}\text { Leucopenia (1) } \\
\text { Immunological failure (1) }\end{array}$ \\
\hline $\mathrm{CBV}-\mathrm{PI} / \mathrm{r}$ & 9 & $\begin{array}{c}\text { Nausea and vomiting (1) } \\
\text { Skin rash (1) }\end{array}$ & Nausea and vomiting (1) & \\
\hline
\end{tabular}

*Due to different causes including: moved to another center, changed treatment, pregnancy, others.

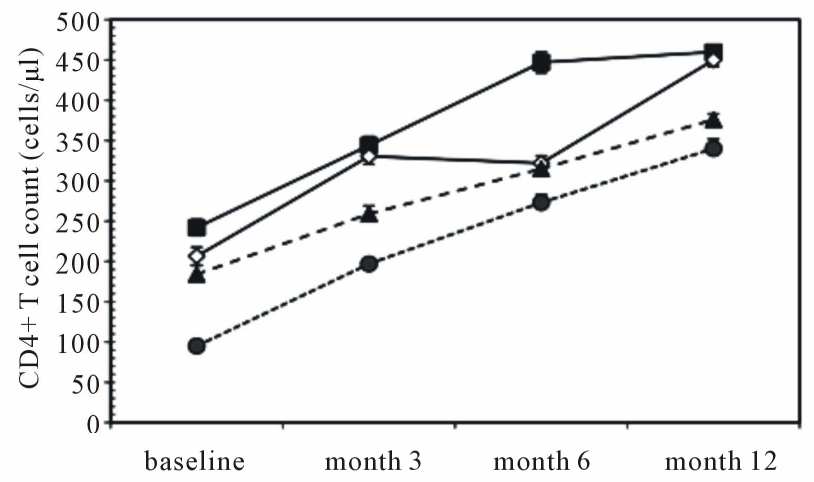

(a)

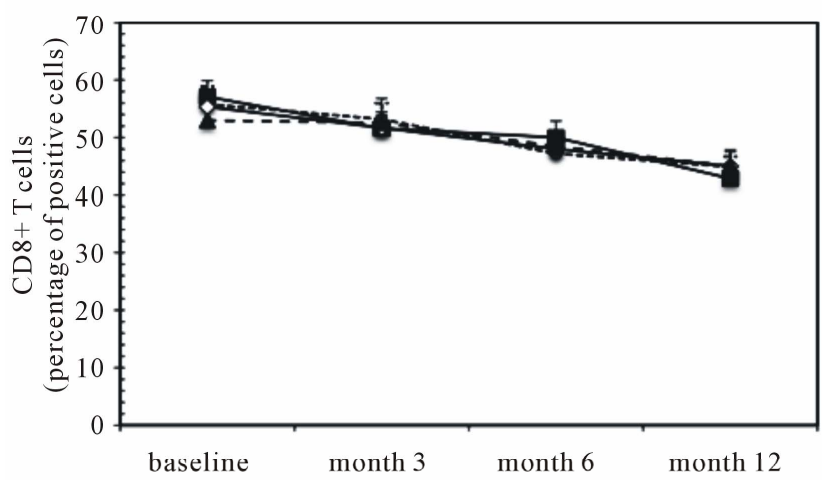

(c)

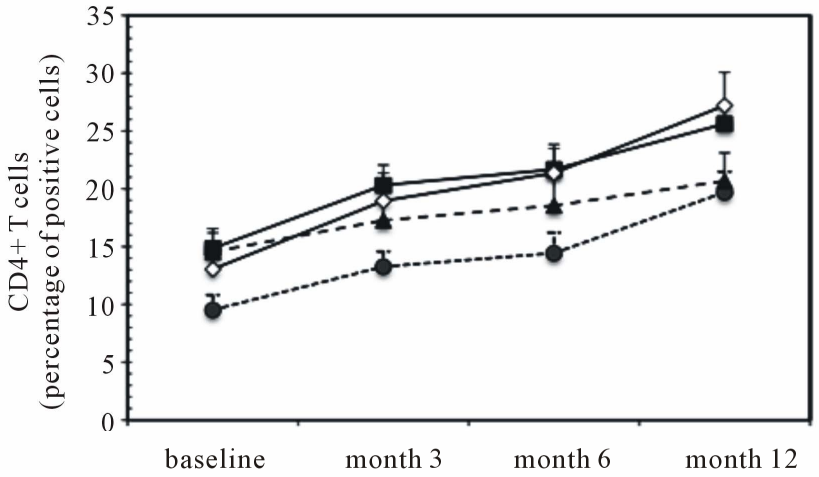

(b)

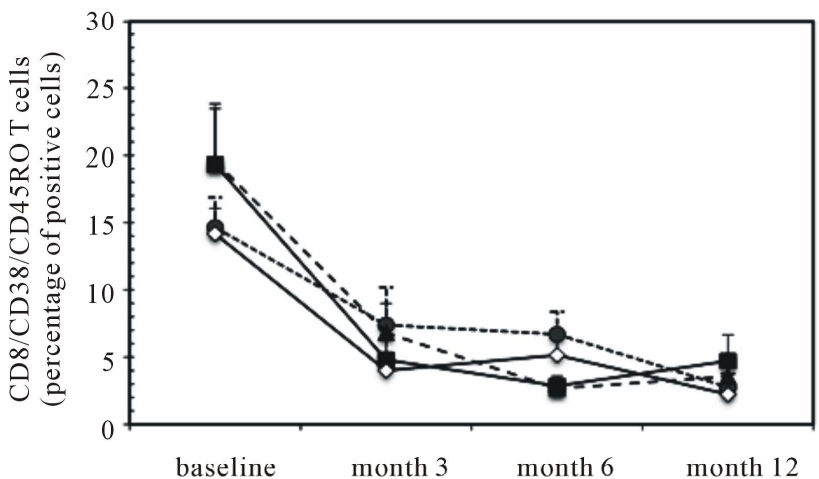

(d)

$\longrightarrow$ TVD $+\mathrm{EFV} \quad---\mathrm{TVD}+\mathrm{Pl} / \mathrm{r} \quad \smile \mathrm{CBV}+\mathrm{EFV} \quad-\mathbf{- a}-\mathbf{C B V}+\mathrm{Pl} / \mathrm{r}$

Figure 1. CD4+ T cell counts (Panel (a)), CD4+, CD8+, and CD8+CD38+CD45+ T cell percentages (Panels (b), (c) and (d)) in HIV-infected individuals treated with TVD + EFV, TVD + PI/r, CBV + EFV or CBV + PI/r evaluated at baseline and after 3 , 6, and 12 months of therapy. Mean values and S.E. are indicated. 
0.003), and CBV-EFV ( $p=0.023)$ patients. This increase was already significant after 3 and 6 months of therapy in TVD-EFV $(p=0.036)$, TVD-PI/r $(p=0.003)$ and CBVEFV $(p=0.050)$ patients, (Figure 1, Panel (b)). Finally, the percentage of $\mathrm{CD} 8+\mathrm{T}$ cells diminished progressively in all patients reaching statistical significance at month 12 compared to baseline, in TVD-EFV $(\mathrm{p}=0.002)$, TVD-PI/r $(p=0.027)$, and CBV-EFV $(p=0.050)$ patients (Figure 1, Panel (c)).

\subsection{Activated CD4+ and CD8+ T Cells}

Activated cells were evaluated analysing CD25 and HLA DRII expression on CD4+ and CD8+ T cells as well as the percentages of circulating CD38/CD45RO-expressing CD8+ $\mathrm{T}$ lymphocytes. No significant differences were detected in $\mathrm{CD} 4+/ \mathrm{CD} 25+, \mathrm{CD} 8+/ \mathrm{CD} 25+, \mathrm{CD} 4+/$ DRII+ or CD8+/DRII+ T cells during the study period in any of the treatment groups (data not shown). In contrast, $\mathrm{CD} 8+/ \mathrm{CD} 38+/ \mathrm{CD} 45 \mathrm{RO}+\mathrm{T}$ cells were significantly reduced after 12 month of therapy compared to baseline in all groups of patients (TVD-EFV: $\mathrm{p}=0.006$; TVD-PI/r: $\mathrm{p}$ $<0.001$; CBV-EFV: $\mathrm{p}<0.001$ and CBV-PI/r: $\mathrm{p}=0.002$ )

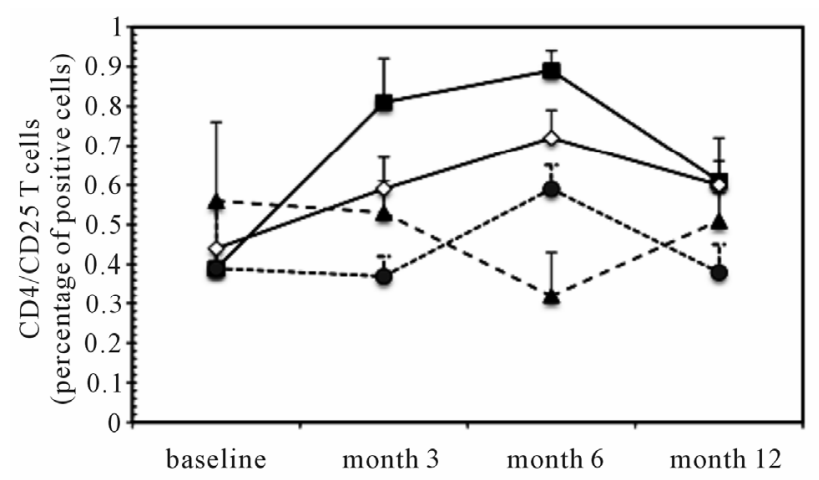

(a)

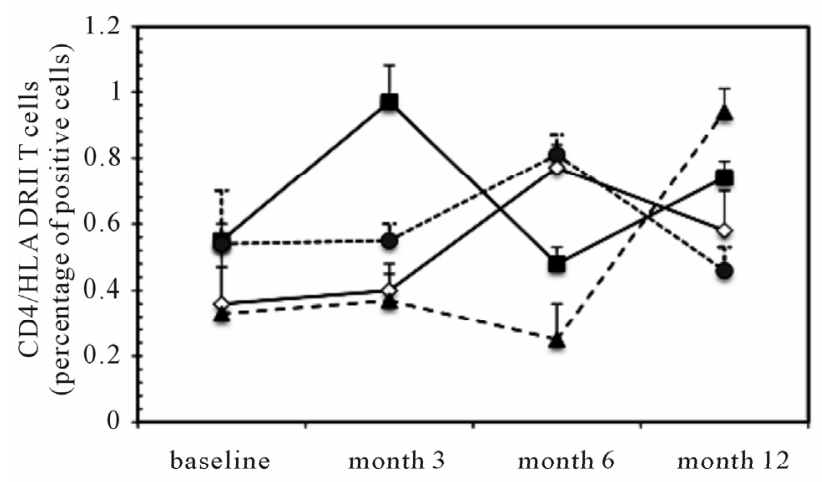

(c)
(Figure 1, Panel (d)). This decrease was possibly faster in EFV-treated patients in whom CD8+/CD38+/CD45$\mathrm{RO}+\mathrm{T}$ cells were reduced already after 3 months of therapy. No significant differences were detected in $\mathrm{CD} 4+/$ CD25+, CD8+/CD25+, CD4+/DRII+ or CD8+/DRII+ T cells during the study period in any of the treatment groups (Figure 2).

\section{Discussion}

During HIV infection, a state of chronic, generalized immune activation is a key determinant of CD4+ $\mathrm{T}$ cell depletion and progression to AIDS [5]. The role of immune activation in HIV infection has generally received less attention than HIV-associated immune deficiency even if recently, immune activation has had renewed attention being a strong, and independent predictor of clinical progression to AIDS $[1,8,9]$. Reduction of immune activation predicts CD4+ T cell increase after ARV better than virus suppression [14]. In the study herein we attempted to verify whether the use of different ARV results in a diverse effect on immune activation.

An optimal suppression of HIV viremia was achieved

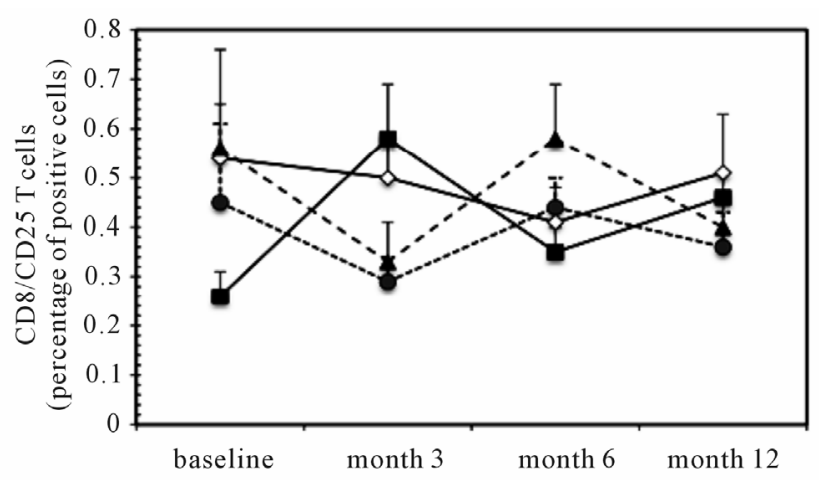

(b)

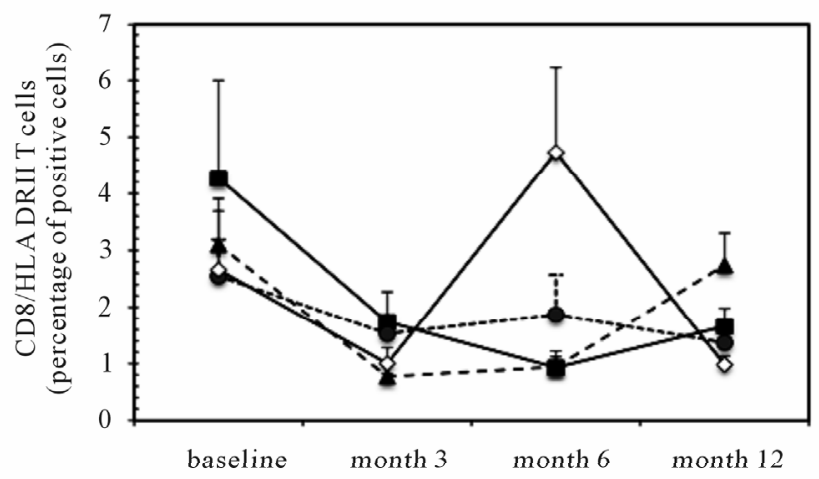

(d)

$$
\text { 一- }-\mathrm{TVD}+\mathrm{EFV} \quad-----\mathrm{TVD}+\mathrm{Pl} / \mathrm{r} \quad \sim-\mathrm{CBV}+\mathrm{EFV} \quad--\mathbf{A}--\mathrm{CBV}+\mathrm{Pl} / \mathrm{r}
$$

Figure 2. CD4+CD25+ (Panel (a)), CD8+CD25+ (Panel (b)), CD4+HLADRII+ (Panel (c)), and CD8+HLADRII+ (Panel (d)) T cell percentages in HIV-infected individuals treated with TVD + EFV, TVD + PI/r, CBV + EFV or CBV + PI/r evaluated at base- line and after 3, 6, and 12 months of therapy. Mean values and S.E. are indicated. 
at month 12 in patients receiving both EFV or $\mathrm{PI} / \mathrm{r}$-based ARV in association with either TVD or CBV, some differences were nevertheless seen when immune parameters were examined. Thus, whereas CD4 counts were significantly increased compared to baseline in patients undergoing all 4 types of ARV, the increases were more impressive in both groups of individuals receiving EFVbased therapies. Additionally, although all types of ARV were associated with a significant reduction of $\mathrm{CD} 8+/$ CD38+/CD45RO+ cells after 12 months of therapy, this effect was possibly faster in individuals undergoing EFVbased therapies. Notably, no differences were seen between baseline and 12 months of therapy in any of the other cell populations examined that are known to be part of the "immuno-activatory phenotype".

The observation that circulating CD8+/CD38+/CD45RO+ $\mathrm{T}$ lymphocytes were reduced in all groups of patients after 12 months of therapy confirms the potency of modern day antiretroviral regimens. The observation that such reduction was possibly more precocious in EFVreceiving individuals allows to speculate that EFV-based therapeutic regimens could be associated with a more favourable immunomodulatory effect. Notably, these results confirm recently published data showing reduced immunoactivation, as measured by the percentage of circulating $\mathrm{CD} 8+/ \mathrm{CD} 38+\mathrm{T}$ cells after 6 months of therapy, in EFV compared to PI/r-treated individuals [15].

Results from the large SMART trial, which evaluated the strategy of interrupting ART in a large population of more than 5000 HIV-infected individuals, clearly showed that the relative risk of non-AIDS-related clinical events is associated with inflammation and immune activation $[16,17]$. Our data, although preliminary, suggest a clinical benefit of EFV-based therapies that would be associated with their possibly earlier ability to down-modulate immune activation.

\section{REFERENCES}

[1] J. V. Giorgi, L. E. Hultin, J. A. McKeating, T. D. Johnson, B. Owens, L. P. Jacobson, R. Shih, J. Lewis, D. J. Wiley, J. P. Phair, S. M. Wolinsky and R. Detels, "Shorter survival in Advanced Human Immunodeficiency Virus Type 1 Infection Is More Closely Associated with T Lymphocyte Activation than With Plasma Virus Burden or Virus Chemokine Coreceptor Usage," The Journal of Infectious Diseases, Vol. 179, No. 4, 1999, pp. 859-870. doi:10.1086/314660

[2] J. V. Giorgi, R. H. Lyles, J. L. Matud, T. E. Yamashita, J. W. Mellors, L. E. Hultin, B. D. Jamieson, J. B. Margolick, C. R. Rinaldo Jr, J. P. Phair, R. Detels and Multicenter AIDS Cohort Study, "Predictive Value of Immunologic and Virologic Markers after Long or Short Duration of HIV-1 Infection," Journal of Acquired Immune Deficiency Syndromes, Vol. 29, No. 4, 2002, pp. 346-655.

[3] P. W. Hunt, J. N. Martin, E. Sinclair, B. Bredt, E. Hagos,
H. Lampiris and S. G. Deeks, "T cell Activation Is Associated with Lower CD4+ T Cell Gains in Human Immunodeficiency Virus-Infected Patients with Sustained Viral Suppression during Antiretroviral Therapy," The Journal of Infectious Diseases, Vol. 187, No. 10, 2003, pp. 1534 1543. doi: $10.1086 / 374786$

[4] K. Smith, E. Aga, R. J. Bosch, E. Connick, A. Landay, D. Kuritzkes, B. H. Gross, I. R. Francis, J. M. McCune, H. Kessler and M. Lederman, "Long-Term Changes in Circulating CD4 T Lymphocytes in Virologically Suppressed Patients after 6 Years of Highly Active Antiretroviral Therapy," AIDS, Vol. 18, No. 14, 2004, pp. 1953-1956. doi:10.1097/00002030-200409240-00012

[5] M. Goicoechea, D. M. Smith, L. Liu, S. May, A. R. Tenorio, C. C. Ignacio, A. Landay and R. Haubrich, "Determinants of CD4+ T Cell Recovery during Suppressive Antiretroviral Therapy: Association of Immune Activation, T Cell Maturation Markers, and Cellular HIV-1 DNA," The Journal of Infectious Diseases, Vol. 194, No. 1, 2006, pp. 29-37. doi:10.1086/504718

[6] M. D. Hazenberg, S. A. Otto, B. H. van Benthem, M. T. Roos, R. A. Coutinho, J. M. Lange, D. Hamann, M. Prins and F. Miedema, "Persistent Immune Activation in HIV-1 Infection Is Associated with Progression to AIDS," AIDS, Vol. 17, No. 13, 2003, pp. 1881-1888. doi:10.1097/00002030-200309050-00006

[7] M. M. Lederman, L. A. Kalish, D. Asmuth, E. Fiebig, M. Mileno and M. P. Busch, “'Modeling' Relationships among HIV-1 Replication, Immune Activation and CD4+ T Cell Losses Using Adjusted Correlative Analyses," AIDS, Vol. 14 , No. 8, 2000, pp. 951-958. doi:10.1097/00002030-200005260-00006

[8] V. Appay, J. R. Almeida, D. Sauce, B. Autran and L. Papagno, "Accelerated Immune Senescence and HIV-1 Infection," Experimental Gerontology, Vol. 42, No. 5, 2007, pp. 432-437. doi:10.1016/j.exger.2006.12.003

[9] J. V. Giorgi, Z. Liu, L. E. Hultin, W. G. Cumberland, K. Hennessey and R. Detels, "Elevated Levels of CD38+ CD8+ T Cells in HIV Infection Add to the Prognostic Value of Low CD4+ T Cell Levels: Results of 6 Years of Follow-Up. The Los Angeles Center, Multicenter AIDS Cohort Study," Journal of Acquired Immune Deficiency Syndromes, Vol. 6, No. 8, 1993, pp. 904-912.

[10] A. Viganó, M. Saresella, S. Rusconi, P. Ferrante and M. Clerici, "Expression of CD38 on CD8 T Cells Predicts Maintenance of High Viraemia in HAART-Treated HIV1-Infected Children. Highly Active Antiretroviral Therapy," Lancet, Vol. 352, No. 9144, 1998, pp. 1905-1906. doi:10.1016/S0140-6736(05)60396-0

[11] P. Deterre, L. Gelman, H. Gary-Gouy, C. Arrieumerlou, V. Berthelier, J. M. Tixier, S. Ktorza, J. Goding, C. Schmitt and G. Bismuth, "Coordinated Regulation in Human T Cells of Nucleotide-Hydrolyzing Ecto-Enzymatic Activities, Including CD38 and PC-1. Possible Role in the Recycling of Nicotinamide Adenine Dinucleotide Metabolites," The Journal of Immunology, Vol. 157, No. 4, 1996, pp. 1381-1388.

[12] A. Savarino, F. Bottarel, F. Malavasi and U. Dianzani, "Role of CD38 in HIV-1 Infection: An Epiphenomenon of $\mathrm{T}$ Cell Activation or an Active Player in Virus/Host 
Interactions?" AIDS, Vol. 14, No. 9, 2000, pp. 1079-1089. doi:10.1097/00002030-200006160-00004

[13] S. G. Deeks, C. M. Kitchen, L. Liu, H. Guo, R. Gascon, A. B. Narváez, P. Hunt, J. N. Martin, J. O. Kahn, J. Levy, M. S. McGrath and F. M. Hecht, "Immune Activation Set Point during Early HIV Infection Predicts Subsequent CD4+ T Cell Changes Independent of Viral Load," Blood, Vol. 104, No. 4, 2004, pp. 942-927. doi:10.1182/blood-2003-09-3333

[14] P. W. Hunt, H. L. Cao, C. Muzoora, I. Ssewanyana, J. Bennett, N. Emenyonu, A. Kembabazi, T. B. Neilands, D. R. Bangsberg, S. G. Deeks and J. N. Martin, "Impact of CD8+ T Cell Activation on CD4+ T Cell Recovery and Mortality in HIV-Infected Ugandans Initiating Antiretroviral Therapy," AIDS, Vol. 25, No. 17, 2011, pp. 21232131. doi:10.1097/QAD.0b013e32834c4ac1

[15] J. M. Miró, C. Manzardo, J. Pich, P. Domingo, E. Ferrer, J. R. Arribas, E. Ribera, J. Arrizabalaga, M. Loncá, A. Cruceta, E. De Lazzari, M. Fuster, D. Podzamczer, M. Plana, J. M. Gatell and Advanz Study Group, "Immune Reconstitution in Severely Immunosuppressed Antiretroviral-Naive HIV Type 1-Infected Patients Using a Nonnu- cleoside Reverse Transcriptase Inhibitor-Based or a Boosted Protease Inhibitor-Based Antiretroviral Regimen: ThreeYear Results (The Advanz Trial): A Randomized, Controlled Trial," AIDS Research and Human Retroviruses, Vol. 26, No. 7, 2010, pp. 747-757. doi:10.1089/aid.2009.0105

[16] A. J. Rodger, Z. Fox, J. D. Lundgren, L. H. Kuller, C. Boesecke, D. Gey, A. Skoutelis, M. B. Goetz, A. N. Phillips and INSIGHT Strategies for Management of Antiretroviral Therapy (SMART) Study Group, "Activation and Coagulation Biomarkers Are Independent Predictors of the Development of Opportunistic Disease in Patients with HIV Infection," The Journal of Infectious Diseases, Vol. 200, No. 6, 2009, pp. 973-983. doi:10.1086/605447

[17] N. G. Sandler, H. Wand, A. Roque, M. Law, M. C. Nason, D. E. Nixon, C. Pedersen, K. Ruxrungtham, S. R. Lewin, S. Emery, J. D. Neaton, J. M. Brenchley, S. G. Deeks, I. Sereti, D. C. Douek and INSIGHT SMART Study Group, "Plasma Levels of Soluble CD14 Independently Predict Mortality in HIV Infection," The Journal of Infectious Diseases, Vol. 203, No. 6, 2011, pp. 780-790. doi:10.1093/infdis/jiq118 